\title{
Impure Hydrazone Preparation from Chicken Dung
}

\author{
Peterson Mutembei Kugeria $^{1 *}$ Peter Waithaka Njoroge $^{2} \quad$ Sylvia Opiyo $^{2} \quad$ Isaac Waweru Mwangi $^{3}$ \\ 1.Department of Physical Sciences, University of Embu, P. O. Box 6 - 60100, Embu, Kenya \\ 2.Department of Physical Sciences, Murang'a University, P. O. BOX 75 -10200, Murang'a, Kenya \\ 3.Chemistry Department, Kenyatta University, P. O. Box 43844-00100, Nairobi, Kenya
}

\begin{abstract}
Hydrazones are strong reducing agents. Some hydrazones like hydrazine are is highly toxic and unstable and are therefore found dissolved in water. Chicken dung contains amines and uric acid that are potential sources of hydrazones. This paper reports on the use of chicken dung as an important raw material for the industrial hydrazones. In this study, we investigated the conversion of amine to amide compounds in chicken dung and later chlorine treatment to produce impure hydrazones. In the preparation, $1.0 \mathrm{~kg}$ of the chicken dung was soaked in 2.0 litres of distilled water for fifteen days. After filtration, the leachate obtained was treated with chlorine gas. The chemical conversion of the compounds in the chicken dung leachate before and after chlorination was monitored using FT-IR and MS. A sample of pure hydrazine hydrate was analyzed using the two techniques and the spectra obtained was used as a reference standard. The findings of this study indicate that chicken dung is rich in aminecontaining compounds that can be converted to amide derivatives under ambient conditions. A comparison of FTIR and MS data before and after chlorination indicated the formation of hydrazones. The findings of this study provide some scientific rationale for using chicken dung as an alternative source of industrial hydrazones.
\end{abstract}

Keywords: Hydrazones, amines, amides, chicken dung.

DOI: $10.7176 / \mathrm{CMR} / 12-7-02$

Publication date:September $30^{\text {th }} 2020$

\subsection{Introduction}

Chicken manure is used as an organic fertilizer. It has been reported to contain about $1.5 \%$ nitrogen and $\mathrm{pH}$ range 5.6 to 9.4 (Foreman \& Long 2013; Kugeria et al. 2018). The two inorganic forms of the material $\left(\mathrm{NH}_{4}-\mathrm{N}\right.$ and $\mathrm{NO}_{3}-\mathrm{N}$ ) account for approximately14 percent of total nitrogen. The remaining 73 percent occurs in the organic form (Sharpley \& Moyer 2000). Nitrogen in chicken manure is found in the form of amide bound protein, amino acids, and other organic forms Kugeria et al. 2018; Sharpley \& Moyer 2000; Barbin et al. 2001; Michael et al. 2012; Oagile \& Namasiku 2010; Mohamed et al. 2011; Hammad \& Hussein 2016). Such compounds contain nitrogen in their inorganic and organic forms. These compounds can be used to prepare hydrazine. Hydrazine has been prepared from ammonia and urea (Allen et al. 2012; Chen \& Soon 2011). When ammonia and urea react with a solution of sodium hypochlorite in alkaline media, hydrazine is obtained. Hydrazine is used to make hydrazones which are very important because of their biological function (Jeewoth et al. 2000; Dharamaraj et al. 2001; Savini et al. 2002).

Studies by Chen and Lim (2002) reported the recovery of precious metals of silver and copper using hydrazine from synthesized wastewater in batch reactors. Kugeria et al. (2018) also reported on the use of hydrazones to reduce copper ion from acid-digested copper ore. This paper reports on the chemical transformation of the chicken dung during the soaking period and subsequent preparation of impure hydrazones solution.

\subsection{Methodology and materials}

2.1 Materials

Hydrazine hydrate, chlorine gas, sodium hydroxide, and de-ionized water were of analytical grade. These chemicals were used to make the solutions for this study and were supplied by Kobian (K) Limited, an outlet of Sigma Aldrich. Chicken dung was obtained from local poultry farmers in Thika, Kenya.

\subsection{Preparation for chicken dung leachate}

A mass containing one kilogram of chicken dung was put into the desiccator and $2000 \mathrm{ml}$ of water added. The content was stirred for 5 minutes to achieve the uniformity of the mixture. The $\mathrm{pH}$ of the mixture was then taken. The content was covered and left to soak for 15 days. During the soaking period, aliquots of the soaked dung were taken at 1, 2, 3, 4, 5, 6, 10, and 15 days (Kugeria et al. 2018). The aliquots were carefully decanted to remove the solid particles and later filtered using filter paper number 4 from Whatman to obtain the chicken dung leachate.

\subsection{Chemical characterization for chicken dung leachate}

Qualitative analysis for the chicken waste solution was done using the FTIR Spectrophotometer model Alpha 10054238 from Bruker. The procedure was carried out by the test method D 7624-10 standard (ASTM, 2010). The instrument was initialized and calibrated by conducting a background scan. The resulting background spectrum 
was compared to a reference spectrum provided in the manufacturer's manual. The analytical grade hydrazine hydrates solution was injected into an FTIR liquid cell for measurement as a standard. In the same manner, a scan for chicken dung leachate prepared in days $1,2,3,4,5,6,10$, and 15 were separately done. After the fifteen days of soaking, $100 \mathrm{ml}$ of the chicken dung leachate was obtained and $\mathrm{pH}$ adjusted to $11 \mathrm{using} 1.0 \mathrm{M}$ sodium hydroxide. The temperature was then raised to $70{ }^{\circ} \mathrm{C}$. Chlorine gas was then bubbled into the solution at a flow rate of 0.5 $0.7 \mathrm{~cm}^{3}$ per second for three minutes (Kugeria et al. 2018). After chlorination, a sample was injected into FTIR and scanned. A comparison of the absorption bands obtained in the spectra of the sample chicken waste with that of the hydrazine hydrate was used for data interpretation. The procedure was repeated by analyzing raw and chlorinated chicken dung leachate and pure hydrazine using mass spectrometer model Waters micromass ZQ ESCI multi-mode ionization enabled. The spectra from both FT-IR and that of MS were used to deduce the chemical transformation before and after chlorination.

\subsection{Results and Discussion}

3.1 Optimization of the equilibration process

Fig. 1 shows the overlay of the results of chicken waste leachate prepared and characterized from day one to day three. The content was later characterized on days 4, 5,6,10, and 15 and the spectra overlay given in fig. 2. Table 1 gives the summary of IR wavenumbers for the possible functional groups found in chicken dung from day one to day fifteen.

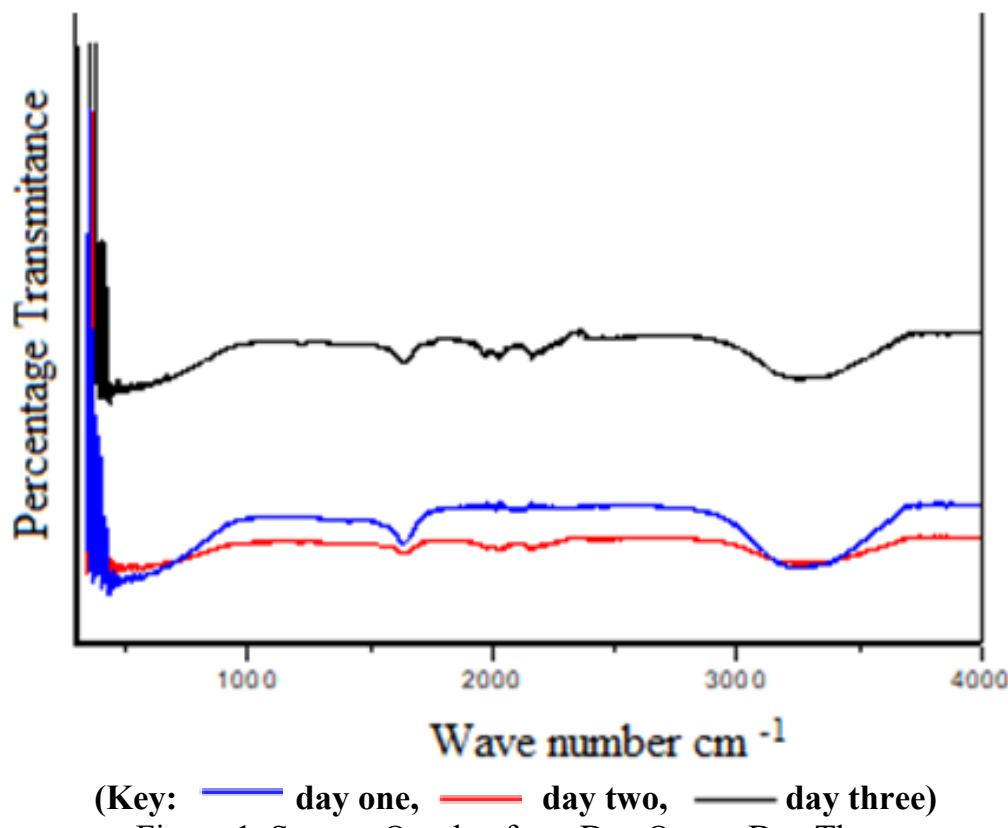

Figure 1. Spectra Overlay from Day One to Day Three 


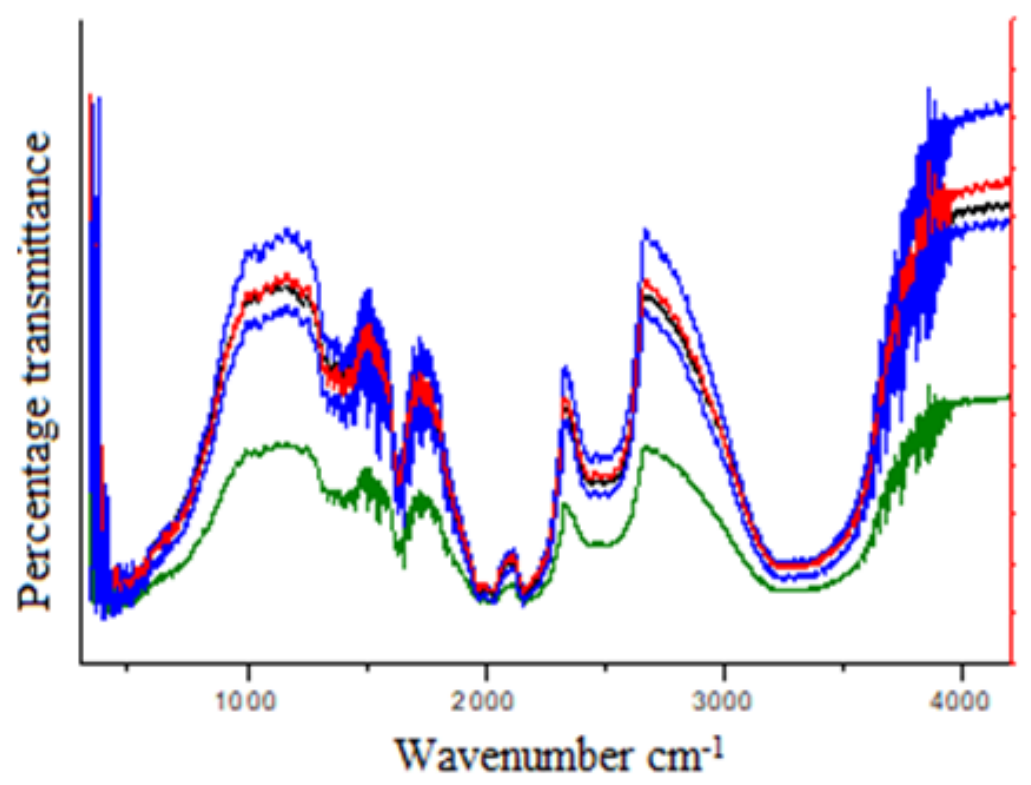
(Key; - day four, - day five, $\longrightarrow$ day six, - day ten,
Figure 2. Spectra Overlay Took on Day 4, 5, 6, 10 and 15

Table 1. Position of IR peaks and their functional groups at day one to fifteen

\begin{tabular}{|c|c|c|}
\hline & Wavenumber $\left(\mathrm{cm}^{-1}\right)$ & Functional groups \\
\hline 1 & $3000-3500$ & $\mathrm{OH}, 1^{\circ} \& 2^{\circ} \mathrm{NH}$ (amines), and C-H stretch \\
\hline 2 & $2400-2600$ & $\mathrm{SH}$ \\
\hline 3 & $2000-2100$ & $\mathrm{CN}$ triple bond stretch \\
\hline 4 & $1500-1750$ & $\mathrm{C}=\mathrm{O} \& \mathrm{C}=\mathrm{N}$ stretch \\
\hline 5 & $1350-1450$ & $\mathrm{C}-\mathrm{H}$ bend \\
\hline
\end{tabular}

The prepared chicken dung leachate in day one to day three contains a peak at 3000 and $3500 \mathrm{~cm}^{-1}$ associated with the presence of $\mathrm{OH}^{-}$functional group from the presence of water or carboxylic acids. Other possible peaks found in this region are for primary and secondary amines resulting from $\mathrm{N}-\mathrm{H}$ and $\mathrm{C}-\mathrm{H}$ stretch. These peaks are typical of amine compounds. The peaks found at the range of $1500-1750 \mathrm{~cm}^{-1}$ are associated with carbonyl and N-H bend (Giguère \& Liu 1952; Kugeria et al. 2018). The presence of carbonyl and that of N-H bond are typical of amide compounds. This shows that the chicken dung contains amine and amide compounds.

From day two another peak at wave number $2000-2100 \mathrm{~cm}^{-1}$ started developing. It is associated with $\mathrm{CN}$ triple bond stretch. From day three another peak at $1350-1450 \mathrm{~cm}^{-1}$ started developing. It is associated with $\mathrm{C}-\mathrm{H}$ bend. The results show that from day four, another peak appeared at wave number $2400-2600$. This peak is associated with SH stretch. The IR data shows that from day 5 to 15 , the chemical transformation was complete with no additional peak. From the results, the carbonyl group and the $\mathrm{CN}$ groups are typical of amides compounds. This shows that amines were possibly aerobically oxidized to amides as shown by equation 1 .

$$
\mathrm{RCH}_{2} \mathrm{NH}_{2}+\mathrm{O}_{2} \rightarrow \mathrm{RCONH}_{2}+\mathrm{H}_{2} \mathrm{O}
$$

This oxidation process increased the amide content in the leachate which was available for conversion to hydrazine.

\subsection{Impure hydrazones}

The FT-IR results of the chicken dung leachate before and after chlorination and that of hydrazine hydrate is given in the overlay spectra in fig. 3 . 


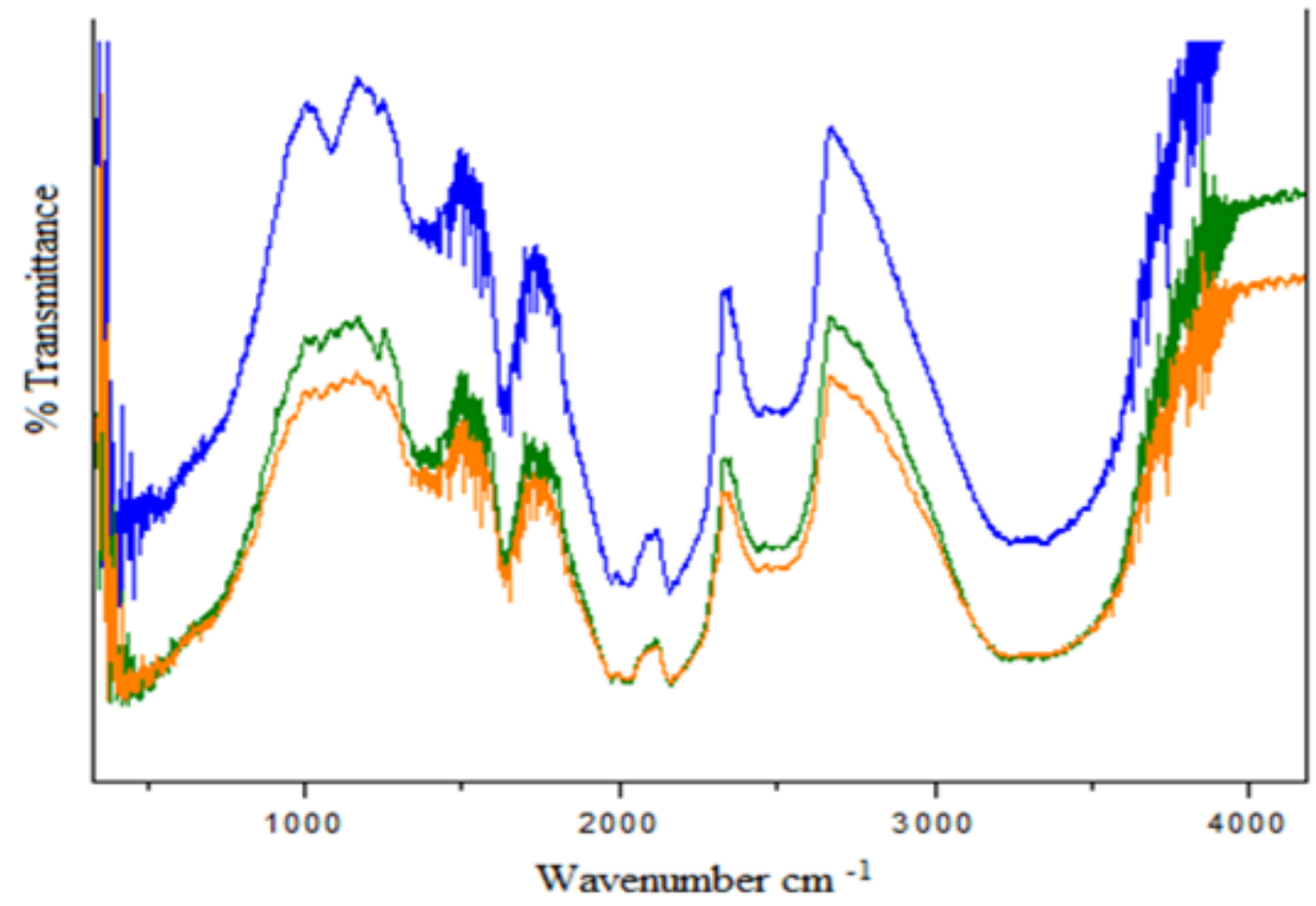

(Key: - Hydrazine hydrate,

Chicken dung after chlorination,

Chicken dung before chlorination)

Figure 3. The Overlay of the IR-Spectra before and after Chlorination

After chlorine treatment, all bands found in chicken dung before chlorination were still present except for a new peak appearing after chlorination at $1000-1250 \mathrm{~cm}^{-1}$ associated with NN stretch (Kugeria et al. 2018). A spectrum of pure hydrazine had all peaks found in chlorinated chicken dung leachate except a peak at range of 1020 to $1090 \mathrm{~cm}^{-1}$, which is within the range of 1000 to $1250 \mathrm{~cm}^{-1}$ (Giguère \& Liu 1952; Kugeria et al. 2018). This shows that after chlorination, the chemical conversion took place in the chicken dung leachate and hydrazones compound was possibly produced.

The presence of carbonyl $(\mathrm{C}=\mathrm{O})$ and $\mathrm{NH}_{2}$ groups show the possible presence of amide (urea) and amine compounds that was oxidized by sodium hypochlorite in chlorinated chicken dung to compound like that of hydrazine as shown in equations 2 and 3 (Chen \& Lim 2002).

$$
\begin{aligned}
& 2 \mathrm{NH}_{3(\mathrm{~g})} \stackrel{\mathrm{NaOCl}}{\longrightarrow} \mathrm{H}_{2} \mathrm{NNH}_{2(\mathrm{aq})}+\mathrm{NaCl}(\mathrm{aq})+\mathrm{H}_{2} \mathrm{O}_{(1)} . \\
& \left(\mathrm{H}_{2} \mathrm{~N}\right)_{2} \mathrm{CO}_{(\mathrm{s})}+\mathrm{NaOCl}_{(\mathrm{aq})}+2 \mathrm{NaOH}_{(\mathrm{aq})} \rightarrow \mathrm{N}_{2} \mathrm{H}_{4(\mathrm{aq})}+\mathrm{H}_{2} \mathrm{O}_{(1)}+\mathrm{NaCl}_{(\mathrm{aq})}+\mathrm{Na}_{2} \mathrm{CO}_{3(\mathrm{aq})}
\end{aligned}
$$

Further analysis of the chicken dung leachate was done using MS technique for confirmation of compound present. The analysis was done using an electron impact ionization of the samples. Also, the biomaterial used was impure. The molecular ion peak could therefore not be used to accurately identify the masses of compounds before and after the chlorination process. The summary of the results of the MS before and after chlorination of soaked chicken dung and that of pure hydrazine are given in table 2. The MS spectra are given in appendices A, B, and C. Table 2. A summary of mass charge value before and after chlorination of soaked chicken dung and that of pure hydrazine

\begin{tabular}{|l|lll|}
\hline & \multicolumn{3}{|l|}{ Percentage abundance for the major peaks } \\
\hline Mass charge ratio (m/z) before chlorination & $122.1,123.1$, & $125.1,126.0$, & $127.0,130.0,133.1$ \\
\hline Mass charge ratio (m/z) After chlorination & $149.0,163.0$, & $167.1, \quad 181.0$ \\
\hline Mass charge ratio (m/z) hydrazine hydrate & \multicolumn{3}{|c|}{149.0} \\
\hline
\end{tabular}

It was observed that before chlorination, chicken dung leachate contained several peaks (table 2 and appendix A). This shows that chicken dung leachate is an impure solution with several fragmented compounds. After chlorination, all $\mathrm{m} / \mathrm{z}$ peaks disappeared and new peaks appeared at $\mathrm{m} / \mathrm{z}$ values given in table 2 and appendix $\mathrm{B}$. This shows that chemical conversion took place. The MS data of pure hydrazine gave only a peak at $\mathrm{m} / \mathrm{z}=149.0$ 
(table 2 and appendix C), which was found in chlorinated chicken dung leachate. This confirms that some compounds (amines and amides) in the chicken dung can be converted to hydrazones after chlorination. The molecular ion peak values were also studied and the results summarised in table 3.

Table 3. The molecular ion peak values

\begin{tabular}{|l|c|l|l|}
\hline & Before chlorination & After chlorination & For hydrazine \\
\hline Molecular ion peak (m/z) & 133.1 & 181.0 & none \\
\hline
\end{tabular}

The molecular ion peak before chlorination is at $\mathrm{m} / \mathrm{z}=133.1$ (appendix A) with low intensity of percentage abundance. This shows that there was more fragmentation of compounds in chicken dung leachate. After chlorination, the molecular ion peak value changed to $\mathrm{m} / \mathrm{z}=181.0$ (appendix B), with high intensity. The high intensity shows that there was less fragmentation of compounds. During chlorination, there was the probability of the addition of chloromethane group $(-\mathrm{CHCl})$ containing the molecular mass of about 48.5 to 133.1 to give a mass of 181.6. This mass is close to the molecular ion peak of the chlorinated chicken dung leachate. This proofs that there was chemical conversion to new compounds with less fragmentation of radical cation.

\subsection{Conclusion}

The above results show that chicken dung can be an alternative source of raw materials for obtaining impure hydrazones. The impure hydrazones can be used as an industrial reducing agent where purity is of little concern. Such industrial use includes extraction of copper from its ore among others (Kugeria et al. 2018).

\section{Acknowledgements}

The author would like to thank Dr. Peter Waithaka, Dr. Waweru Mwangi, and Dr. Sylvia Opiyo for their contribution during the study. The author also acknowledges Kenyatta University where the practical were done.

\section{Conflict of interest}

The authors declare that there is no conflict of interest.

\section{References}

Allen, C. L., Chhatwal, A. R., Williams, J. M. (2012), Direct amide formation from inactivated carboxylic acids and amines. Chemical Communications, 48(5) $666-668$.

American Society for Testing and Materials (ASTM) (2010), 2010 Annual Book of ASTM Standards - Volume 03.01 Metals - Mechanical Testing; Elevated and Low-Temperature Tests; Metallography, A.S.T.M. (2010).

Barbin, E. L., Santos, T. C., Spano, J. C. E., Guimaraes, L. F., and Pecora, J. D. (2001), Solvent action on sodium hypochlorite on bovine pulp and physio-chemical properties of resulting liquid. J. Braz Dent., 12(3), $154-$ 179.

Chen, J. P., Lim, L. L. (2002), Key factors in chemical reduction by hydrazine for recovery of precious metals, Chemosphere, (49), 363-370.

Chen, J. P., Soon, H. H. (2011), Oxidative amide synthesis directly from alcohols w amines, Journal of Organic and Biomolecular Chemistry, (9), 20 - 22.

Dharamaraj, N., Viswanathamurthi, P., Natarajan, K. (2001), Ruthenium (II) complexes containing bidentate Schiff bases and their antifungal activity. Transition Metal Chemistry, (26), $105-109$.

Foreman, P., and Long, C. (2013), "Chickens in the Garden: Eggs, Meat, Chicken Manure Fertilizer, and More". Mother Earth News, 1-5.

Giguère, P. A., Liu, I. D. (1952), On the infrared Spectrum of hydrazine. The Journal of Chemical Physics, (20), $136-142$

Hammad, K. H. A., Hussein, H. A. (2016), Effect of NPK and chicken manure on the productivity and some growth components of squash (cucurbita pepo l.). ARPN Journal of Agricultural and Biological Science, 11(6), $230-235$.

Jeewoth, T., Li, K., Wah, H., Brown, M. G., Ghoorohoo, D., Babooram, K. (2000), Synthesis and antibacterial/catalytical properties of Schiff bases and Schiff base metal complexes derived from 2, 3diaminopyridine. Synthesis and Reactivity in Inorganic and Metal-Organic Chemistry, (30), 1023 -1038.

Kugeria, P. M., Mwangi, I., Wachira, J., Njoroge, P. (2018), Copper extraction by wet chemical method, Journal of Sustainable Mining, (17), 202-208.

Michael, T. M., Phiwokwakhe, D., Paul, K. W., and Tajudeen, O. O. (2012), Effects of Chicken Manure on Growth, Yield and Quality of Lettuce (Lactuca sativa L.) 'Taina' Under a Lath House in a Semi-Arid Sub-Tropical Environment, American-Eurasian Journal of Agriculture. \& Environmental. Science, 12(3), 399 - 406.

Mohamed, A. A., Saifel, D. M. E., Elamin, A., Magid, E. (2011), Effects of chicken manure as a component of organic production on yield and quality of eggplant (Solanum melongena L.) fruits. Journal of Science and Technology, 12(4), 1-8.

Oagile, D., Namasiku, M. (2010), Chicken manure-enhanced soil fertility, and productivity: Effects of application 
rates. Journal of Soil Science and Environmental Management, 1(3), 46 -54.

Savini, L., Chiasserini, L., Gaeta, A., Pellerano, C. (2002), Synthesis, and anti-tubercular evaluation of 4Quinolylhydrazones. Bioorganic and Medicinal Chemistry, (10), 2193 - 2198.

Sharpley, A. N., Moyer, B. (2000), Forms of phosphorus in manures and composts and their dissolution during rainfall. Journal of Environmental Quality, (29), $1462-1469$.

\section{APPENDICES}

Appendix A: Spectrum of chicken dung leachate before chlorination

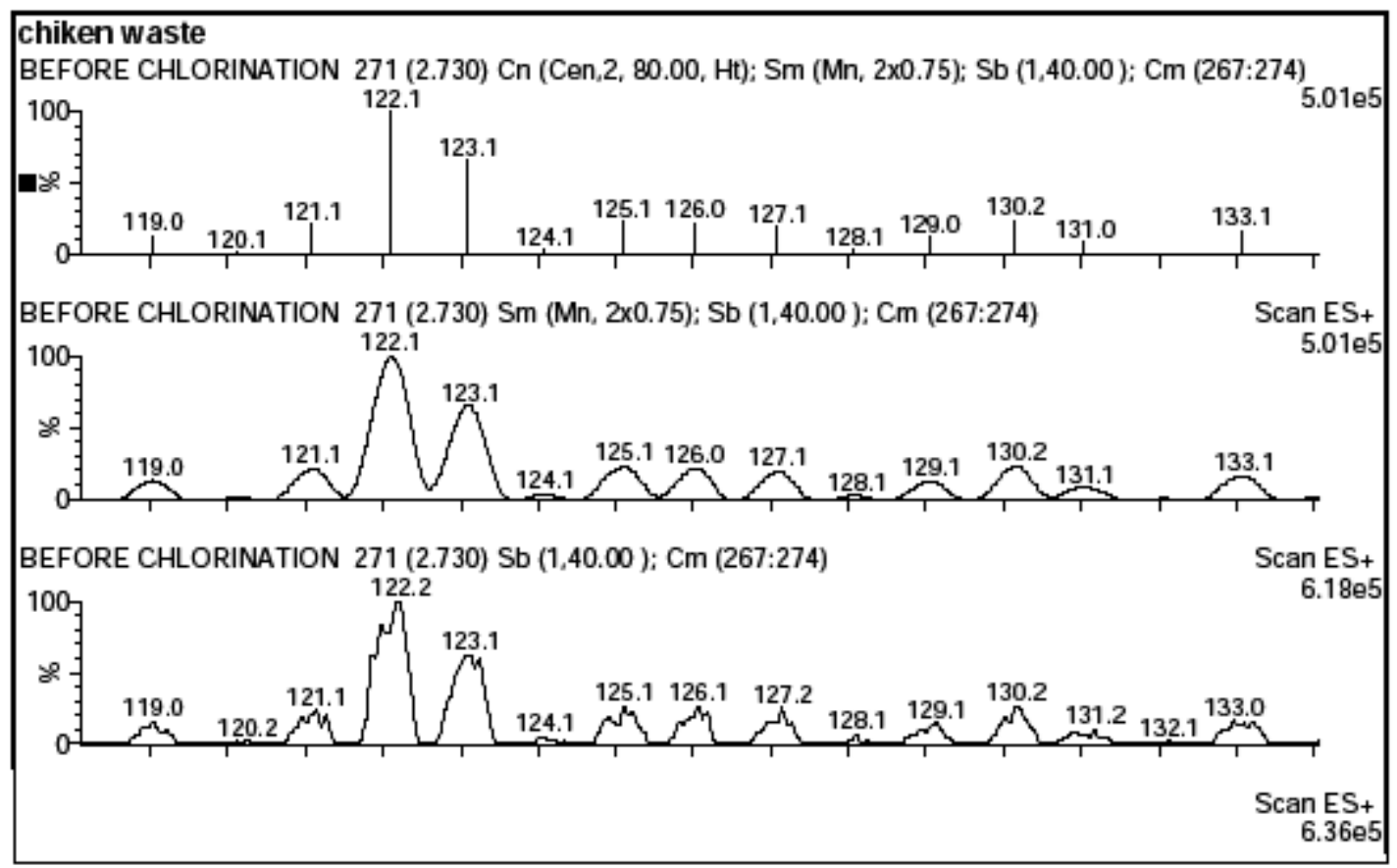

Appendix B: Spectrum of chicken dung leachate after chlorination

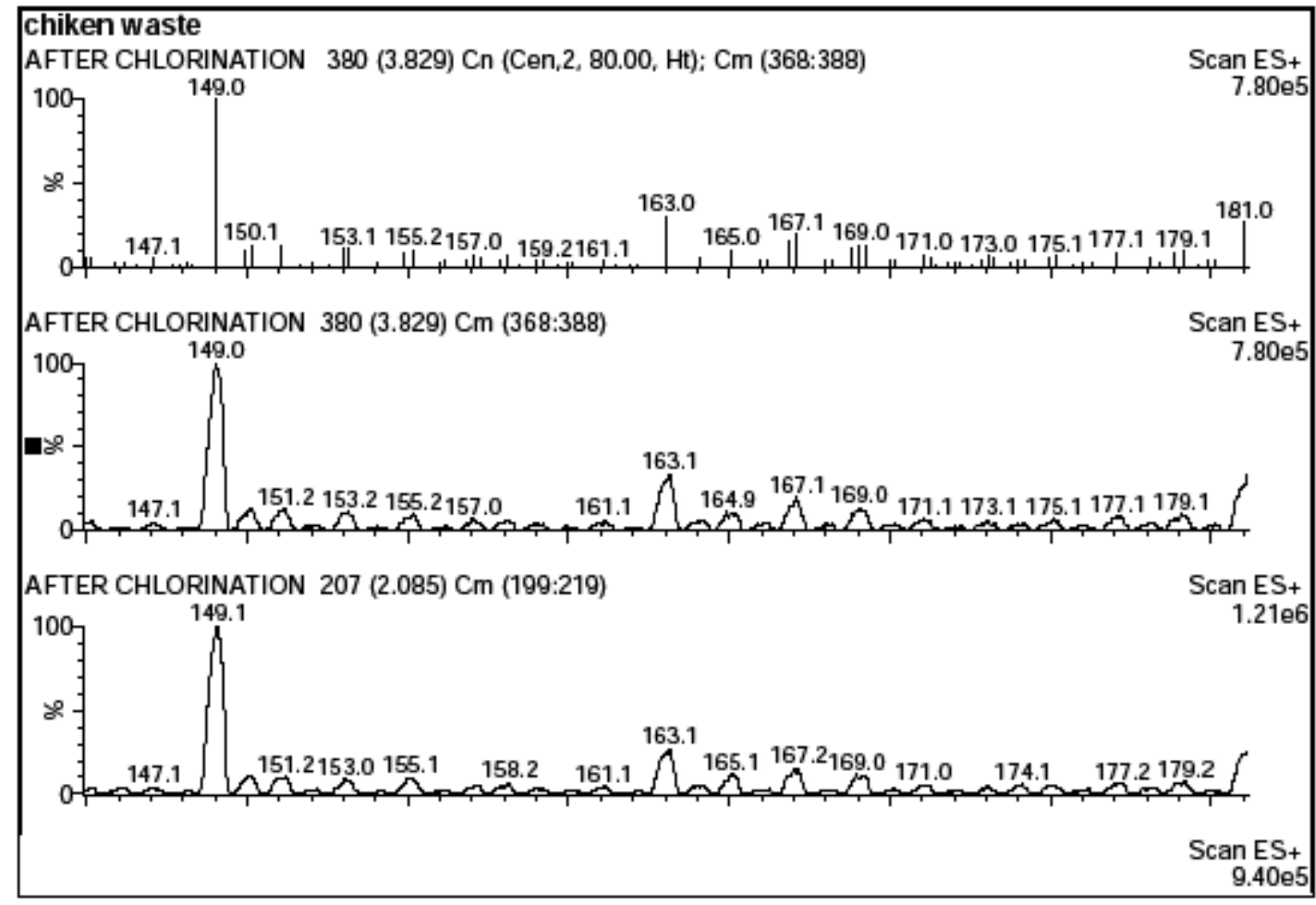


Appendix C: Spectrum of pure hydrazine

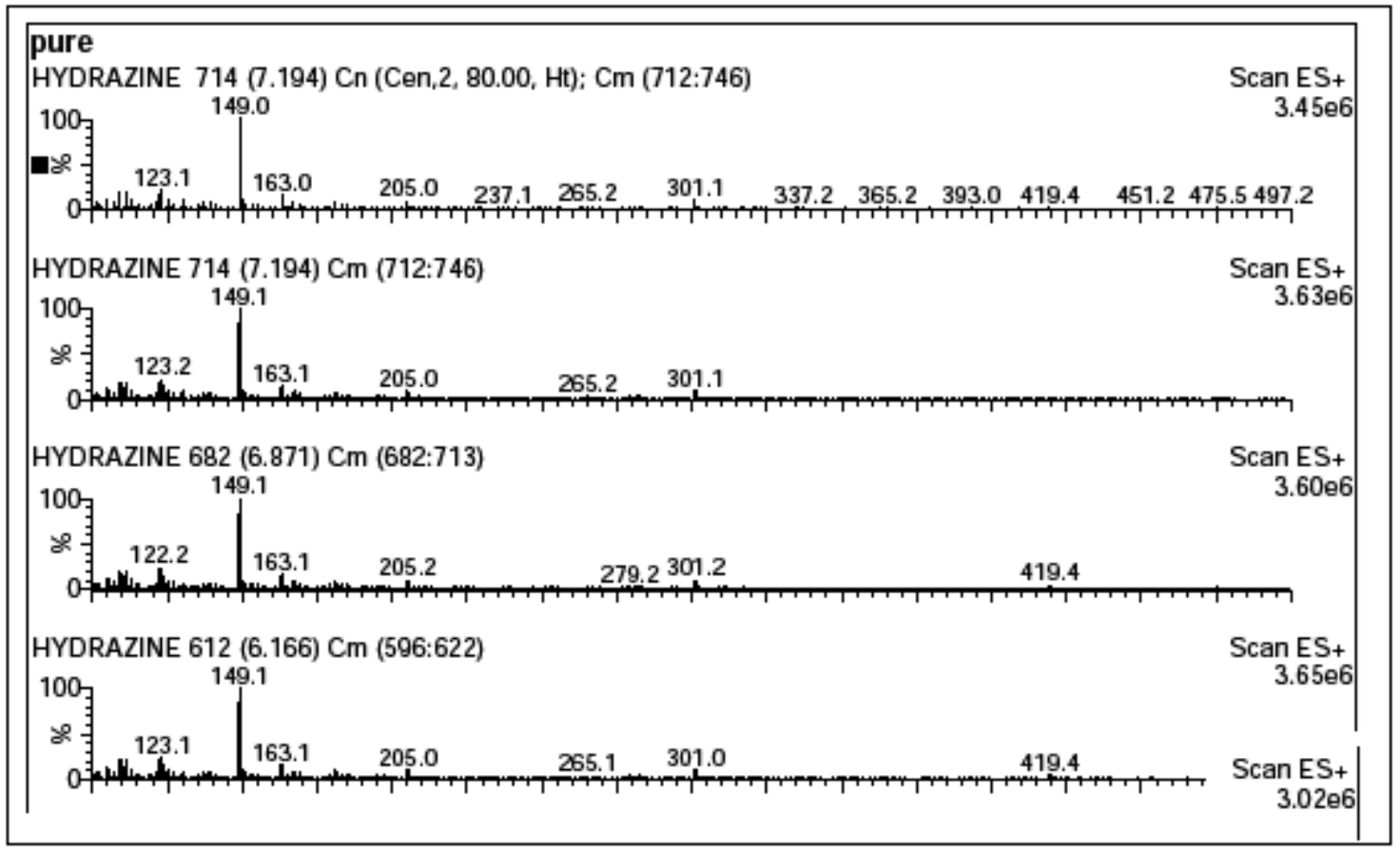

